\title{
Blank, E. A. (2020). Easy Marriage Counselling: 52 Self-Guided Exercises to Deepen Your Relationship. California: Rockridge Press.
}

\author{
Reviewed by Sandra Letshwenyo-Maruatona, University of Botswana
}

The book "Easy Marriage Counselling: 52 Self-Guided Exercises to Deepen Your Relationship" is written by a marriage, couples and family therapist. In a simple and realistic manner, she presents different topics that couples struggle with over the course of their married life. Blank sets the tone by articulating a broad range of issues from personality development, sexuality and intimacy, finances, communication, decision-making, health and several others. The book focuses on assisting couples who may be going through marriage difficulties or who just want to strengthen their relationship. She uses her book to include aspects that are necessary in assisting couples in re-examining their life events and transitions and help them to learn more about themselves, their partners and their marriages. The book comprises fiftytwo sessions and she begins each session by either sharing her experiences in the counselling room or sharing an anecdote, which makes it easier for readers to appreciate the issues under discussion.

Blank, in a very practical manner, ends each session with a series of direct and practical questions and exercises meant to assist couples in reflecting on their own experiences. This Choose an item.helps them to re-examine their situation and possibly experience personal and collective transformation. She exposes couples to the realities of life and helps them to kickstart by engaging in a dialogue about their situation in order to introspect on what they are currently going through in their relationships and to assess whether what they are doing is 
negatively or positively impacting their relationships. As a firm believer in reality therapy and the philosophy of realism, I very much identify with her style of discussing issues by assisting couples to be realistic about their challenges and to explore realistic solutions.

She discusses the importance of understanding each other's personality and how it profoundly influences a couple's ability to develop and sustain relationships. She proceeds from a humanist perspective to assist couples in understanding and exploring basic existentialistic questions such as, "Who am I? Who is my partner? and she argues that because of inherited qualities, people have to accept the fact that they perceive issues differently. She advises that "knowing your partner's personality can help you understand the motivations for their actions or the reasons they might feel a certain way" (p. 6). For example, Introverts on the one hand may close up, avoid addressing conflict, and leave issues unresolved while Extroverts, on the other hand, may deal with conflict by talking loudly and engaging in addressing issues. She cautions couples to accept individual differences and still co-exit.

One aspect I found particularly outstanding is her emphasis on the significance of acknowledging that one cannot change the other person. This is a common mistake made by many couples and she stresses the need for people to co-exist by respecting each other's value systems. Another critical point that she also highlights is the impact of childhood experiences on current and future relationships. Her arguments are congruent with many counselling and psycho-social and cognitive theorists who demonstrate the profound impact that childhood experiences can have on relationships. Blank proposes amicable ways in which couples can find sustainable solutions in handling conflict with civility and respect for each other. Whilst different authors have suggested strategies to effectively address conflict, the most striking feature of this book is the way she demonstrates how some people engage in an avoidance 
mode whilst others engage in a fighting mode as influenced by their past experiences. She emphasizes that knowledge of the partner's background may assist in appreciating that keeping silent or speaking loudly about issues may not necessarily depict disrespect, arrogance or rudeness.

She does an impressive job by discussing the role the structure of different types of families, family dynamics and friends can play in influencing a marriage relationship. In terms of family dynamics, her experience with couples and research has shown that in heterosexual relationships, women are more likely than men to perform the bulk of tasks related to household management such as child care. This inequality around the division of labour tends to cause enormous stress among couples. Blank suggests that "spouses who perceive a sense of shared responsibility in household tasks are more satisfied in their relationships" (p. 33). One interesting aspect of this book is that although it is written in a western cultural context, it discusses issues such as polygamy and lesbian, gay, bisexual, and transgender (LGTB) issues that are relevant to many socio-cultural backgrounds including the African context. The author's strength lies in her philosophical view on the tolerance of plurality of people and plethora of relationships beyond the heterosexual family and she highlights the strengths and challenges of each relationship.

The uniqueness of the "Easy Marriage Counselling" book is its focus on issues that can be considered as potential threats to the stability of relationship such as the work/life balance, growing apart, and past relationships, which are rarely included in most counselling books. Other aspects covered include sexual orientation, which research has shown may change overtime. Blank persuasively illustrates that from her experience some people who were initially identified as heterosexuals may be attracted to people of the same sex. I find this aspect 
very significant and something for many to appreciate and for families to embrace in their discussions, especially in African settings where there is a general assumption that sexual orientation remains constant, especially among heterosexuals and people become shocked when they discover the change.

Blank's book, like most marriage counselling books, emphasizes the importance of communication between partners. In her discussion, she carefully guides couples on being mindful and considerate to each other's feelings when making decisions (even when those decisions are considered minor) because partners need to work as a team rather than as opponents. She stresses quality (value) over frequency (quantity) of communication. She says "I often find that people don't need to communicate more, they need to communicate better" (p. 134). Blank is successful at opening couples' eyes to common challenges of marriage possibilities and the realities of life. Through her exceptional writing, she goes beyond other marriage counselling books by discussing very unique topics such as serious illness in the family, trauma, grief, loss and death that are part and parcel of everyday life, yet are often avoided. They are usually brought up only when couples encounter such situations. She demonstrates to couples that experiencing these situations can disrupt the family's functioning ability. The author acknowledges that it is hard to ordinarily talk about these issues but recommends that conversations about them is very critical. She encourages couples to deliberately plan to discuss them and support each other or even help one another get therapy where necessary.

The strength of this book lies in the fact that the Blank combines well known literature with personal and professional anecdotes to develop her arguments in a helpful and balanced manner to help couples see her view of the world as well as provide opportunities for them to 
learn more about themselves, their partners, and their marriages. She simplifies and walks the readers through all these complex relational issues and engages them in exercises that are relevant to all types of relationships. At the end, she leaves the readers informed and content about some ways to effectively handle relationship issues. Another distinctive feature in her writing is her presentation style where she concludes each session with a series of nonjudgmental practical exercises that are relevant to all couples, whether one is straight or gay, monogamous or polyamorous, and with or without children. Her non-judgemental attitude in her presentation of the issues is also evident where she gives people options to draw from but does not prescribe how they should handle their relationships.

This book is an excellent read, designed to effectively assist couples in managing a variety of relationships. It is a very useful, easy to use tool for novices as well as experienced marriage counsellors and therapists to guide their interventions. As a student of counselling with some experience of being in a counselling room, it becomes very easy to identify with the issues being discussed and I find sufficient guidance from her suggested interventions. Overall, I personally view the book as a captivating read for anyone. I found it very informative and I highly recommend it not only for assisting in managing conflict in marital relationships but relationships in general at family level, the workplace, and other contexts. The only shortcoming of the book is that in some instances the author tends to raise interesting issues, heightens the reader's expectations and then suddenly ends the discussion. It could have been helpful to provide additional readings for her audience so that they can further explore other ways of addressing the issues of interest to them. 